\section{Correspondence}

https://doi.org/10.11646/zootaxa.5004.3.6

http://zoobank.org/urn:1sid:zoobank.org:pub:69698904-731C-41E2-A623-A1E70130FBE6

\title{
Leeuwenia hollisi sp.n. (Thysanoptera, Phlaeothripinae) from New Guinea, with the tenth abdominal segment exceptionally long
}

\author{
LAURENCE A. MOUND \\ Australian National Insect Collection, CSIRO, PO Box 1700, Canberra, ACT 2601

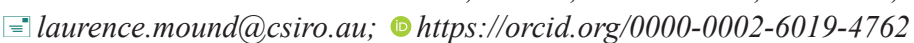

Species of Leeuwenia, an Old World tropical genus of leaf-feeding thrips, have been termed the "long-tubed thrips", in view of the extraordinary length of their tenth abdominal segment (Mound 2004). Adults of these species sometimes raise the tube over the body and project it forwards over the head. The anus is at the apex of this tube, and exudates from the anus seem to be used by these insects as repellants when under threat (Suzuki et al. 1988; Mound \& Tree 2021). The length of the tube varies greatly between species, from no more than five times its basal width in L. aliceae from Australia, to 22 times the basal width in L. arbastoae from the Philippines. The body-size of the species described below is about the same as that of arbastoae, but the tube is more slender and thus almost 25 times as long as its basal width. Among the 30 species of the genus Leeuwenia (ThripsWiki 2021) the host plants are not known for 12 species, but 11 are recorded from plants in the family Myrtaceae, and seven species are recorded each from one of seven other plant families (Mound 2004). The new species described here was found on the leaves of a species Schefflera, a genus in the family Araliaceae, thus further extending the range of plant families with which this thrips genus is associated.

\section{Leeuwenia hollisi sp.n.}

Female macroptera. Body bicoloured (Fig. 1), head brown but paler postero-laterally (Fig. 3), pronotum pale with translucent major setae; meso and metathorax brown; tergites II-VIII yellow laterally with posterior segments increasingly brown medially, IX and tube brown; antennal segments III-IV largely yellow, V-VI brown distally (Fig. 2); fore wing pale with brown median longitudinal band on basal half; all tarsi yellow, fore tibiae yellow, mid and hind tibiae brown with extreme apex yellow. Head more than twice as long as median width (Fig. 3), postocular small, arising laterally far behind eyes; maxillary stylets retracted mid-way into head, mouth cone not extending across prosternum. Antennae 8 -segmented, III with one sense cone, IV with 3 long, slender sense cones (Fig. 2). Pronotum weakly sculptured (Fig. 6); epimeral setae long and arising from small tubercle; notopleural sutures not quite complete. Prosternal basantra absent but bearing one or two setae; mesopresternum complete; metathoracic sternopleural sutures absent. Metanotum with one pair of setae medially (Fig. 4); reticulation longitudinal on anterior half, equiangular on posterior half, reticles with internal markings. Fore wing typical of genus, parallel-sided, cilia closely spaced without duplicated cilia; sub-basal setae short and further apart than their length. Pelta broadly triangular (Fig. 5); tergites II-VII each with 2 pairs of sigmoid wing-retaining setae, lateral setae not elongate; VII-IX with group of discal setae medially; tube almost 25 times as long as basal width, about 3 times as long as head; with numerous setae except near base and apex, these setae no longer than tube width.

Measurements (holotype female in microns). Body length 5300. Head, length 550; width 230; postocular setae 40. Pronotum, length 230; width 380; major setae: anteromarginals 35 , anteroangulars 50 , midlaterals 50 , epimerals 125 , posteroangulars 35 . Fore wing length 1800; sub-basal setae length 30, 65, 50. Tergite IX setae S1 60. Tube length 1800; basal width 75. Antennal segments III-VIII length, 175, 150, 145, 110, 80, 60.

Male macroptera. Very similar to female in colour and structure but smaller, body length 4500. Sternite VIII almost fully occupied by large pore plate.

Specimens studied. Holotype female, New Guinea, Easy Highlands Province, Gahavisuka, from underside of Schefflera leaves, 27.ix.1987 (David Hollis), in the Natural History Museum, London. Paratypes: one female three males taken with holotype (female and male in Australian National Insect Collection, Canberra).

Comments. Most species in this genus are reputed to have only two sense cones on antennal segment IV (Mound \& Tree 2021), whereas this species has three long slender sense cones on IV that extend almost to the mid-point of segment 
$\mathrm{V}$. The head is longer than in most species of the genus, and the only species with a tube of similar length is L. arbastoae from the Philippines (Reyes 1994). However, the holotype of arbastoae is uniformly brown, with the head shorter and the postocular setae and tube longer (400, 100, 2010 microns respectively), and the metanotum has a transverse band of 10 small setae anterior to the median pair (Fig. 7). In the key to Australian species of this genus (Mound \& Tree 2021) the new species will track to convergens Hood, but that has only two sense cones on antennal segment IV and the tube is only 13 times as long as its basal width.

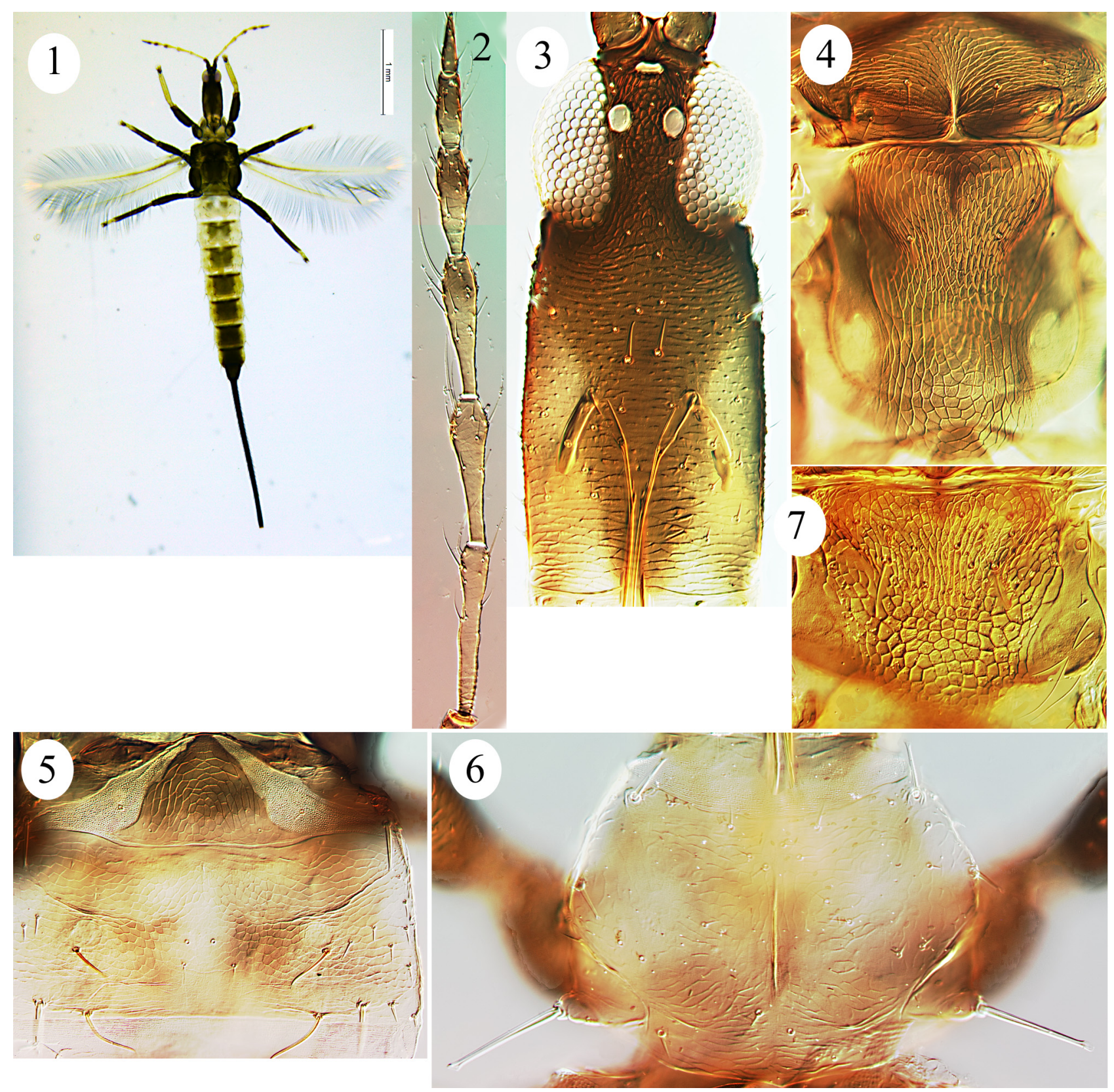

FIGURES 1-7. Leeuwenia species. L. hollisi sp.n. holotype female 1-6: (1) female; (2) antenna; (3) head; (4) meso and metanota; (5) pelta and tergite II; (6) pronotum. (7) L. arbastoae holotype female metanotum.

\section{Acknowledgements}

I am grateful to Paul Brown of the Natural History Museum, London, for the loan of many thrips slides, to Alice Wells by whom Figure 1 was produced, and to the Zootaxa reviewers and editor for helpful comments. 


\section{References}

Mound, L.A. (2004) Australian long-tailed gall thrips (Thysanoptera, Phlaeothripinae, Leeuweniini), with comments on related Old World taxa. Australian Journal of Entomology, 43, 36-45.

https://doi.org/10.1111/j.1440-6055.2004.00406.x

Mound, L.A. \& Tree, D.J. (2021) Structural variation among species of Leeuwenia (Thysanoptera, Phlaeothripinae) with three new species from Australia. Zootaxa, 4903 (3), 439-447.

https://doi.org/10.11646/zootaxa.4903.3.9

Reyes, C.P. (1994) Thysanoptera (Hexapoda) of the Philippine Islands. The Raffles Bulletin of Zoology, 42 (2), $107-507$.

Suzuki, T., Haga, K., Kodama, S., Watanabe, K. \& Kuwahara, Y. (1988) Secretions of thrips II. Secretions of three gall-inhabiting thrips (Thysanoptera: Phlaeothripidae). Applied Entomology and Zoology, 23, 291-297.

https://doi.org/10.1303/aez.23.291 